\title{
Remote and Hands-on: Informal Environmental Health Science Education in a Socially Distant World
}

\author{
Caitlin M. Fallone, MA', Katrina S. Korfmacher, PhD', Lisa Brosnick, MSEd², and Dina G. Markowitz, PhD',2 \\ ${ }^{1}$ Department of Environmental Medicine, University of Rochester, Rochester, NY and ${ }^{2}$ Science Take-Out, LLC, Pittsford, NY
}

Keywords:Informal science education, environmental health sciences, science outreach

Publication Date: July 19, 2021

DOI: https://doi.org/10.15695/jstem/v4i2.04

\begin{abstract}
The COVID-19 pandemic has created significant challenges for informal health science education, which traditionally involves face-to-face programming. We describe the adaptation of hands-on environmental health science kits for online and socially distanced informal education with diverse audiences. These hands-on science kits were traditionally used for in-person, whole group instruction. Because the kits include all the materials needed to complete the activities, they provide hands-on science experiences without the need for a science lab facility. We developed a logistics plan for online use of the kits, taking into account the use of technology, kit distribution, virtual instruction, and audience engagement. We also developed COVID-19-safe practices for in-person instruction that supported social distancing while engaging learners in hands-on science. The strategic adaptation and creative implementation of these kits allowed us to engage our community's youth in environmental health learning during the isolated and uncertain times of the pandemic. Lessons learned from this experience may inform future efforts to provide remote, interactive informal science education to respond to diverse learners' needs.
\end{abstract}

\section{INTRODUCTION}

Informal environmental health education is frequently based on hands-on, face-to-face programming. The COVID-19 pandemic has led to significant challenges to this mode of science learning (Young and Garcia, 2020). Unable to use hands-on labs due to remote or socially-distanced learning guidelines, science teachers also struggled to provide an alternative lab experience for students. The alternatives included not conducting any kind of lab experience, "paper and pencil" labs, recording lab results and sharing with students, and utilizing virtual labs (computer-based simulations). However, it is widely accepted that hands-on learning has significant benefits over computer-based simulations (Kontra et al., 2015; Zacharia and Olympiou, 2011). We sought to continue our science outreach programming during the COVID-19 pandemic by adapting hands-on learning experiences to remote and socially distanced approaches.

The Community Engagement Core (CEC) of the University of Rochester Environmental Health Sciences Center has a longstanding collaboration with Science Take-Out (STO), a University of Rochester start-up company. We adapted our community outreach methods for COVID-19-safe practices by using hands-on kits from Science Take-Out for remote and in-person learning. These hands-on science kits were traditionally used for in-person instruction - for example in science classrooms or science clubs, with participants working in pairs or small groups on the activities. The kits require no preparation and include all the materials needed to complete the activities and simulated experiments. Thus, the kits allow for hands-on science experiences without the need for a science lab facility. The kits also use simulated "wet lab" materials that substitute safe reagents to avoid exposure to potential chemical or biological hazards. These "wet lab" simulations provide safe ways to engage participants in hands-on learning about current topics in science (Markowitz and Holt, 2011). Use of the kits during the COVID-19 pandemic provided us with the opportunity to continue offering hands-on programming to diverse groups of informal environmental health science learners despite pandemic restrictions. 


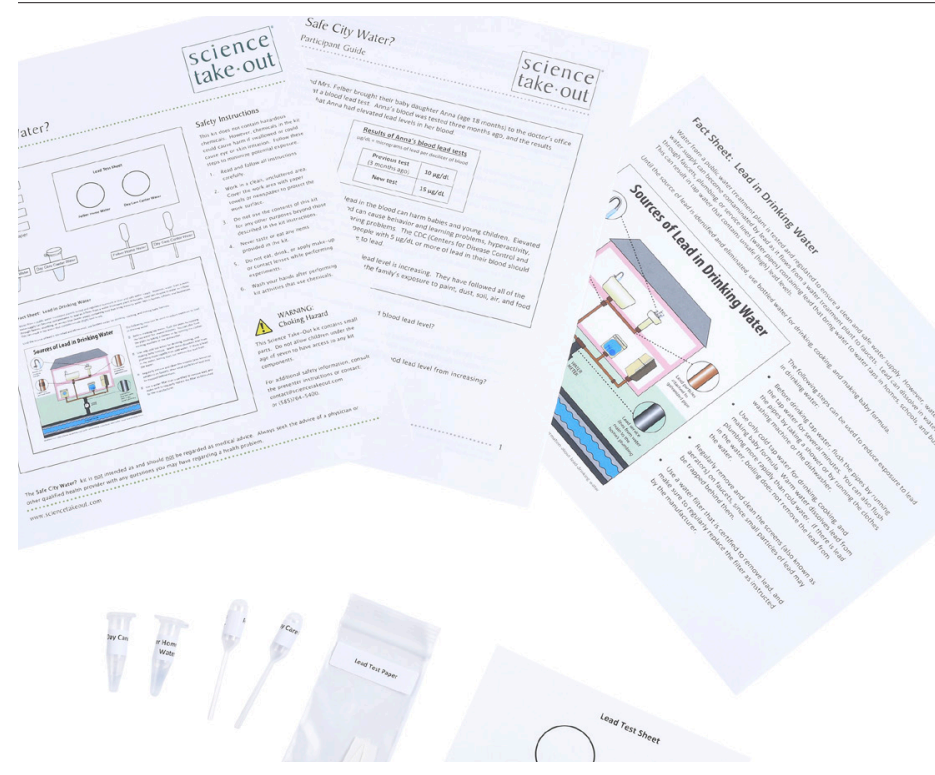

Figure 1. Safe City Water. Kit materials.

\section{METHODS AND RESULTS}

Descriptions of the Kits. The CEC and STO previously collaborated to develop eight environmental health science kits for informal education with diverse audiences as well as two kits on e-cigarettes (vaping) for secondary school audiences. Of these, we selected two kits for our hands-on, COVID-19-safe informal education programs - Safe City Water and Are Flavored E-Cigarettes Harmful? These two topics (lead in drinking water and vaping) were particularly timely and relevant for the groups of young learners we worked with. Pre-COVID-19 (prior to March 2020), participants completed these kits face-to-face, working with a partner to do the hands-on activities, to read the questions in the printed hands-outs, and to discuss their answers with their partner. The kits were evaluated, pre-COVID-19, using written surveys completed on-site by the kit participants and written surveys completed by the kit presenters. The evaluation process for in-person (pre-COVID-19) use of these kits indicated a high level of engagement and learning by participants.

Safe City Water. The Safe City Water kit (Figure 1) focuses on the environmental health risks of lead in tap water. The kit is designed to engage participants in learning the following concepts:

- Water from a public water treatment plant is tested and regulated to ensure a clean and safe water supply.

- Water from a public water supply can become contaminated by lead as it flows from a water treatment plant to faucets.

- People can and should reduce their exposure to lead in drinking water.
This kit follows the real-life scenario of parents who have an 18-month-old daughter with an elevated blood lead level. Participants perform simulated lead testing of tap water samples ( $\mathrm{pH}$ buffer solutions) from the family's home and the baby's day care center, using simulated "Lead Test Paper" (phenolphthalein test paper) (Figure 2). Participants also use a fact sheet with an infographic to identify sources of lead in drinking water and to learn about ways to reduce lead exposure from tap water.

Pre-COVID-19 (before March 2020), the Safe City Water kit was used by a variety of community-based groups, such as the Girl Scouts, youth environmental programs, neighborhood health programs, and citizen scientist groups. The kits were also used in professional development workshops for pediatricians, health educators, and students who educate communities about environmental health issues. Teenagers who used the Safe City Water kit, pre-COVID-19, commented that "I learned a lot", that the kit "is fun and easy to do", and "I liked learning ways I can get rid of lead in my water". Many teens were unaware of the danger of lead in drinking water- "I didn't know that you can get really sick from lead in your water." When asked to give examples of what they learned from using the Safe City Water kits, teenagers indicated things like "I learned some of the developmental consequences of lead exposure in children especially", "lead can be in any water or pipes in your building", and "I need to run my [tap] water just in case it has lead in it".

Are Flavored E-Cigarettes Harmful? The Are Flavored E-Cigarettes Harmful? kit (Figure 3) focuses on the impact of e-cigarette flavoring chemicals on lung cellular health.

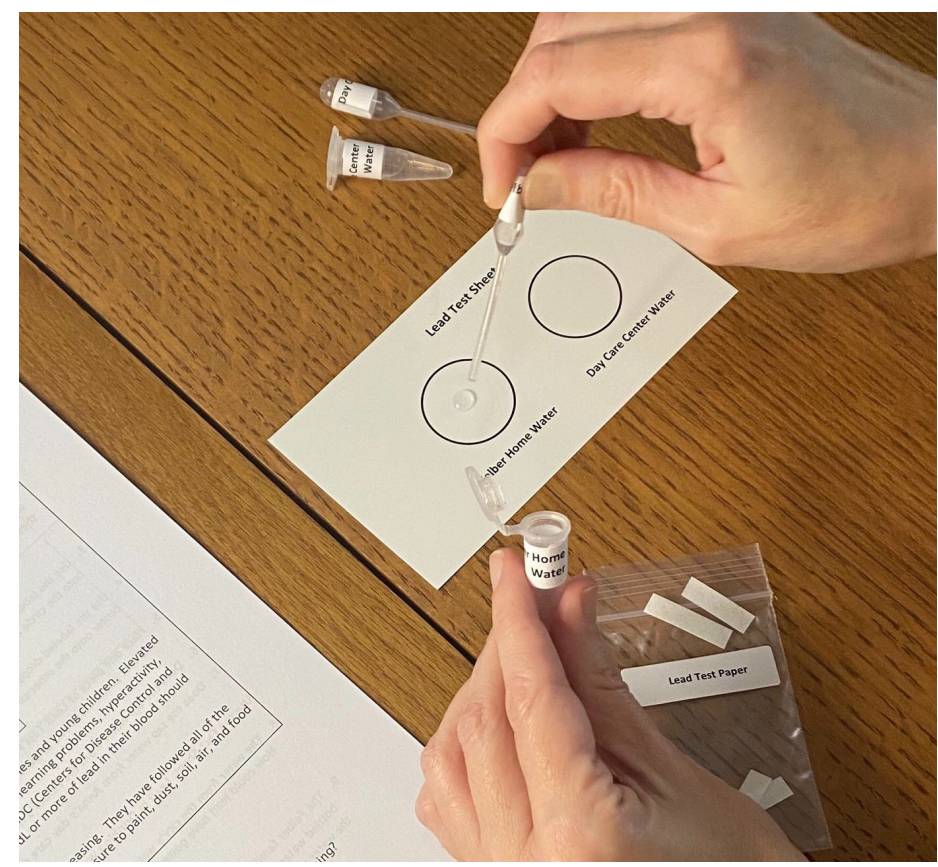

Figure 2. Safe City Water kit. Simulated testing for lead in tap water. 


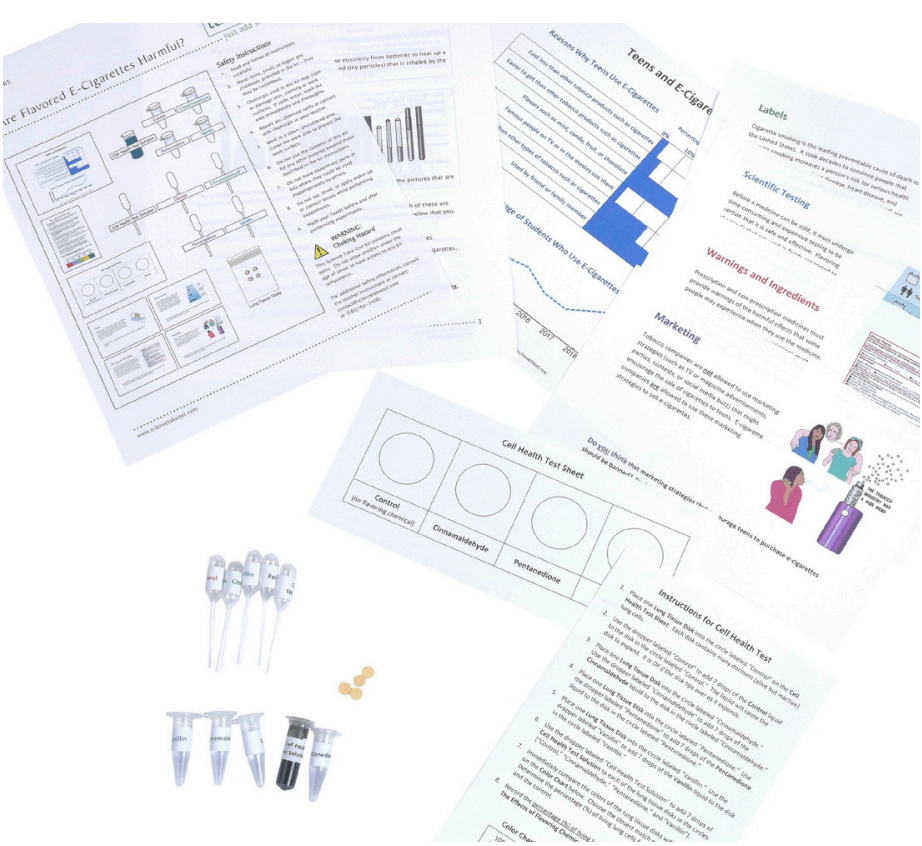

Figure 3. Are Flavored E-Cigarettes Harmful? Kit materials.

The kit is designed to engage participants in learning the following concepts:

- Although some flavoring chemicals are safe to eat, scientific research suggests flavoring chemicals may not be safe to inhale.

- E-cigarette use (vaping) may cause short and long-term damage to the respiratory system.

- To protect people's health, e-cigarette research and regulation is needed.

With this kit, participants conduct hands-on simulated lab tests to determine the effect that flavoring chemicals used in e-cigarette liquids ("vape pods" or "e-liquids") have on lung cells. They use simulated "lung cells" (compressed sponges) that are treated with "flavoring chemicals" (pH buffers) that simulate the chemicals used to create cinnamon, butter, and vanilla flavors. Participants also use information on e-cigarette advertising to consider how flavorings and advertising promote e-cigarette use in teens.

Pre-COVID-19 (before March 2020), the Are Flavored E-Cigarettes Harmful? kit was used by classroom teachers in high school and middle school science and health classes. The kit was also used in school-based and outreach programs for at-risk youth and in professional development workshops for teachers and school staff who work with at-risk youth (Figure 4). Evaluation surveys completed by classroom teachers who field-tested the Are Flavored E-Cigarettes Harmful? kit indicated that this kit had an impact on their students' understanding of the risks associated with vaping/e-cigarettes:

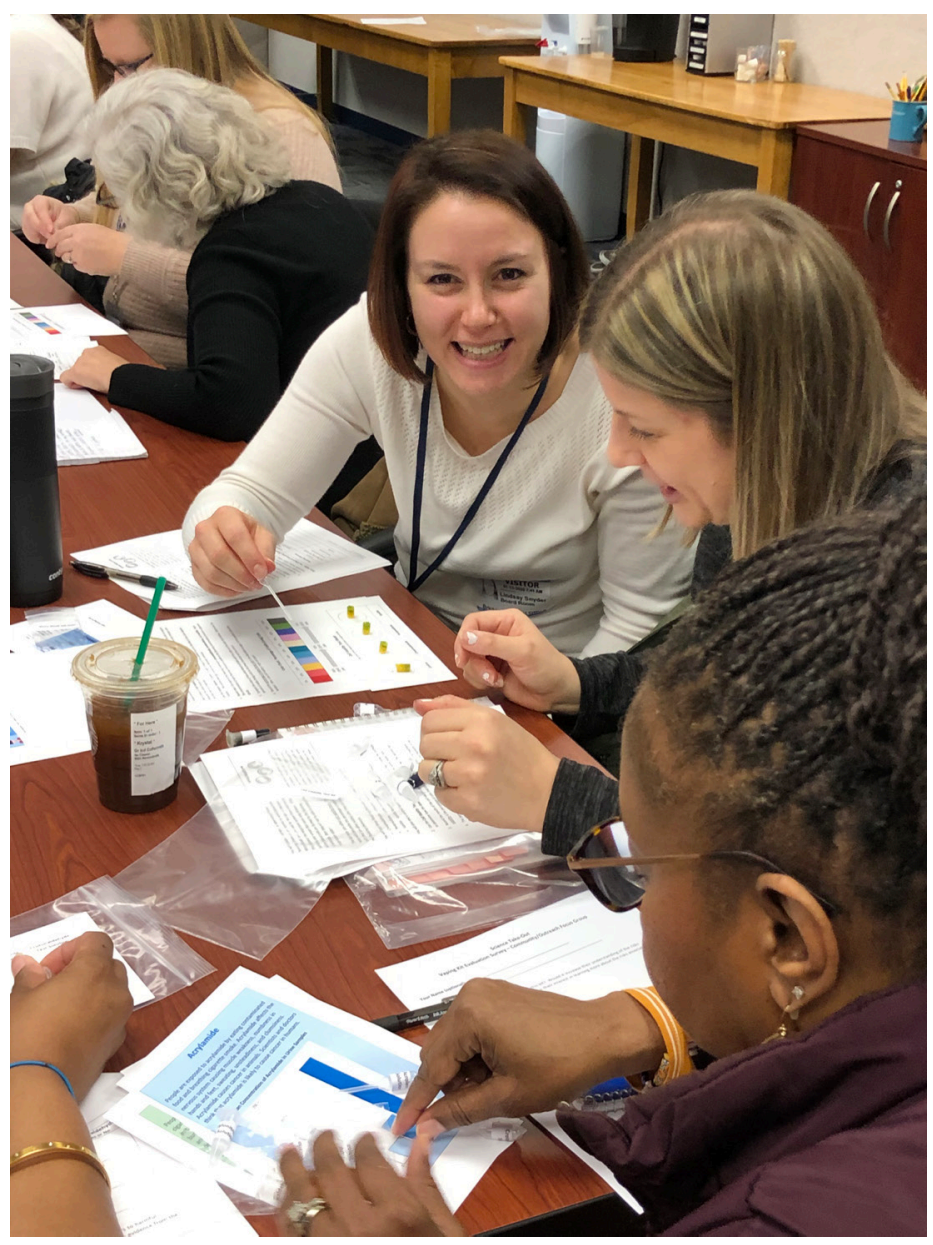

Figure 4. Are Flavored E-Cigarettes Harmful? Teacher workshop pre-COVID-19.

"[The kit] opened their eyes to the idea that chemicals that are safe to eat are not safe to inhale, and how the claims that e-cigs were supposed to be a safe alternative to smoking is false!"

"They were shocked at how harmful the flavorings can be to the lungs."

"They were definitely shocked to see the results. They were saying things like 'Eew that's disgusting. I can't believe how much damage that does' and 'Why would anyone ever want to do this?',

"They were surprised that e-flavorings are harmful, not regulated or warnings on labels."

"The students saw the risks and were eager to share their experiences with other students and family members. Parents expressed gratitude that this subject matter was being explored/discussed."

"Several times during each class I heard 'This is killing so many lung cells.' Then, when discussing with our counselor, they said things like, 'It is so bad for our lungs. ", 
Use of the Kits during the COVID-19 Pandemic. The onset of the COVID-19 pandemic in mid-March 2020 brought an abrupt halt to our in-person science education and outreach programming. Despite the uncertainties of the COVID-19 pandemic, the Community Engagement Core (CEC) was committed to addressing our community's environmental health concerns through educational programming. We describe below examples of how we adapted and implemented the Safe City Water kit and the Are Flavored E-Cigarettes Harmful? kit for hands-on use with diverse audiences in remote and socially-distanced settings. For each group of remote participants, we created a logistics plan that considered the use of technology, kit distribution, program instruction, and audience engagement. We also developed COVID-19safe practices for in-person programs that supported social distancing while engaging learners in hands-on science.

\section{American Lung Association, Reality Check Program} (Are Flavored E-Cigarettes Harmful?). Through previously established relationships, we continued our collaborations with the American Lung Association's Reality Check youth action program. Reality Check is composed of youth-based extracurricular groups that focus on advocating for tobacco policy change and peer education of tobacco. These programs have satellite groups located across the United States. We worked with two Reality Check groups, one group based in New Jersey, and the other group in Plattsburgh, NY.

We led two Reality Check sessions in May 2020 for 23 high school-aged teens in grades 10-12. Each Reality Check group participated at their individual home locations, via the web-based conferencing program Zoom. We coordinated kit mailings with the Reality Check groups' adult leaders to ensure that kits arrived at the leaders' homes with time to be distributed to the participants in advance of the Zoom session. We also provided the Reality Check leaders with information about the Zoom links, the session times, and how the participants should prepare for the online sessions. For example, the Reality Check leaders made sure that the participants had their kits, a laptop or tablet with Zoom, access to a table or counter to work at, and adequate lighting.

The Reality Check sessions were led by a CEC staff member. Their preparations included setting up a ring light so that the kit components and activities could be visualized clearly through Zoom, utilizing a lapel microphone for optimal sound, and positioning the laptop camera in the appropriate location to ensure all participants could clearly see the kit activities. The CEC staff member facilitated the kit activities by guiding the participants through the readings and the hands-on experiments. Each step of the kit was completed together, with the CEC staff member demonstrating the kit while the teen participants did the activities at their own individual locations. Participants engaged in semi-structured discussions during and after the kit activities. These discus- sions were guided by the kit, such as discussing the activity that simulated the toxic effects of flavoring chemicals on lung cells. Participants also talked about their real-life experiences, including witnessing their peers vaping, and how the kit helped them understand why vaping is dangerous.

At the end of each session, the Reality Check groups' adult leaders completed surveys to provide qualitative feedback on the session. (Note: We did not collect feedback from the teens.) The Reality Check group leaders were asked to describe how their Reality Check teens responded to the kit, what challenges or problems were observed, and how the kit could be revised to overcome these challenges. The Reality Check leaders provided very positive feedback, indicating that the kit was a very valuable hands-on learning experience that was especially appreciated during the COVID-19 pandemic crisis.

"The youth enjoyed the tangible experience of this experiment and how we can use this as evidence when we educate community members. Our youth can draw from this experience in the future and create community change. I think this was great for all experience levels and gave them an experience I could not give otherwise."

"Our students responded to this experience in a positive way. Participating in an active experiment from their home gave them tangible evidence about the risks of vaping."

“This was a wonderful 'hands-on' experience, which was very valuable during this current medical crisis."

"I feel the students that participated will present this valuable information to their peers."

Rochester Museum and Science Center (Safe City Water). Our CEC staff led an online (Zoom) session in July 2020 for the Rochester Museum and Science Center (RMSC) Curiosity Camp. The RMSC Curiosity Camp was held onsite at the RMSC facility. We coordinated with the RMSC Curiosity Camp administrator to set up technology for a wholegroup session, and to ship the kits to the RMSC location.

The group of 11 participants aged 9-11 were located in one large auditorium at the RMSC facility. They were seated at their own tables, socially distanced with at least 6 feet between each participant. A CEC staff member led the session through a Zoom video feed that was projected on one large screen located at the front of the auditorium. The CEC staff member facilitated the kit activities remotely by guiding the RMSC group through the readings and the hands-on experiments. Each step of the kit was completed together, with the CEC staff member demonstrating the kit while the participants did the activities all together at the RMSC location. 
The RMSC participants could see and hear the CEC staff member on the large screen as they worked through the kits. However, the CEC staff member struggled to see, hear, and interact with all the participants because they were spread out over the entire auditorium. It was challenging to facilitate the hands-on activities without being able to see fine details of the individual participants as they worked through the kit activities. The CEC staff was not able to speak to individual participants to answer their specific questions or provide individual support. Also, the acoustics of the auditorium made it difficult to hear many of the comments and made group discussions difficult. We did not collect feedback from the RMSC program participants.

\section{Girl Scouts of Western New York (Are Flavored} E-Cigarettes Harmful?). A common community partner connected the University of Rochester CEC team to the Girl Scouts of Western New York (GSWNY) organization. GSWNY leadership was looking for ways to engage their youth members while maintaining COVID-19-safe practices. Towards the end of the COVID-19 pandemic "stay at home" period in August 2020, public health policy allowed for inperson events to resume with specific guidelines from the Centers for Disease Control, New York State, Girl Scouts of America, and the University of Rochester Medical Center.

CEC staff led an in-person event for a Girl Scout troop of six girls between the ages of 10-13. This event was held outdoors at a local county park, which ensured social distancing. We coordinated with the GSWNY troop leader in advance of the session, to determine the logistics for the event, including materials needed for COVID-19-safe practices, such as providing hand sanitizer, masks, and wipes, and the seating arrangements required to provide adequate social distancing.

Each GSWNY participant was stationed at her own picnic table at the park. The picnic tables were approximately 10 feet apart - far enough apart for social distancing, but close enough together so that everyone could hear each other for discussions. Participants and CEC staff wore masks. CEC staff facilitated the kit activities, leading the participants through the sections of kit and the hands-on activities. Each participant had her own kit, so they did not need to share any of the materials or printed handouts. CEC staff walked in between the picnic tables, while maintaining a safe distance, to answer questions and provide support as the participants worked through their kits.

As the GSWNY participants completed the kit activities, they discussed their findings and questions with other participants and the CEC staff. Participants' conversations were rich with real-life experiences, including describing experiences with peers vaping on school buses as well as older siblings and parents vaping. The Girl Scout troop leaders, who were also parents of two of the participants, noted that they have received notifications from the school regarding vaping policies. One participant shared with CEC staff that she found it difficult to discuss the topic, due to her father having a lung illness that was exacerbated by his vaping use.

Seneca Park Zoo, Urban Ecologist Program (Safe City Water). The Seneca Park Zoo's Urban Ecologist Workforce Development program introduces Rochester City School District high school students to careers in environmental science and ecology and empowers them to be ambassadors and role models for the environment and sustainability in their own neighborhoods.

CEC staff led an online (Zoom) session in August 2020 for 12 Urban Ecologist program participants in grades 11 and 12. We corresponded with the Urban Ecologist program coordinator to make sure that each participant had their own computer or tablet set up with Zoom. We delivered the kits to the coordinator, who distributed the kits to each participant.

CEC staff facilitated the kit activities by guiding the participants through the readings and the hands-on experiments. Each step of the kit was completed together, with CEC staff demonstrating the kit while the participants did the activities at their own individual locations. Participants engaged in semi-structured discussions during and after the kit activities. After the participants finished doing the Safe City Water kit, the Urban Ecologist program coordinator led a virtual tour of his City of Rochester home for the teens to observe the different water sources in the home and to determine what the fixtures and pipes were made of. This impromptu activity supported the lessons learned within the kit and provided real-world examples on how these kits can provide insight to individuals' own experiences.

At the end of this session, the participants provided verbal feedback on the session in group and individual discussions with CEC staff. They expressed appreciation for the kits providing context to environmental health issues they had learned about in the Urban Ecologist program, as well as feedback on how the kits were "fun" and made the concept of lead exposure in water easier to understand. The Urban Ecologist program coordinator commented that, "I felt like they [Urban Ecologists] got a lot out of it. It is always cool to see how a lab can lead the conversation in different directions."

\section{National Association of Biology Teachers (Are Flavored E-Cigarettes Harmful?). CEC and STO staff led a science} teacher webinar via Zoom in January 2021, hosted by the National Association of Biology Teachers (NABT). The NABT webinar modeled strategies for using hands-on lab materials in online and hybrid classrooms and in teacher professional development programs. The webinar was also designed to support teachers in using hands-on lessons aligned with the Next Generation Science Standards (NGSS, 2013). The webinar highlighted activities in the Are Flavored E-Ciga- 
rettes Harmful? kit that focus on the NGSS science practices of analyzing data and constructing explanations about the effect of vaping on the respiratory system; for example, involving students in analyzing data from research studies to determine the danger of respiratory system damage associated with vaping.

Thirty-four teachers participated in the webinar-most were high school teachers, several were middle school teachers or college faculty. The webinar was advertised through NABT, via emails sent to NABT members. We corresponded with the NABT Executive Director to arrange the logistics of the webinar and to obtain the mailing addresses of the participants. Kits were mailed to the participants in advance of the webinar. We also emailed the participants several times to provide them with details and reminders about the webinar, to make sure they received their kits, and to make sure they had the proper technology.

We started the webinar as a whole group, to provide background information about the kit and instructions for how the teachers would be working on their kits via Zoom. Because of the large size of the group, we used the "chat" function of Zoom for general questions and comments and we used the "raise hand" function for a participant to be recognized for conversation. The teachers worked through the parts of the kit in small groups of 3-4 in Zoom breakout rooms, which were assigned randomly. In the breakout rooms, they completed one part of the kit at a time, discussing each part of the kit with their group. After each part, teachers then gathered as a whole group to discuss that part of the kit.

Teachers seemed engaged throughout the webinar. The smaller breakout groups allowed for conversations about the kits and conversations about the struggles of teaching during COVID-19. The breakout rooms generally worked well-although it was difficult to monitor the rooms, since the Zoom chat function did not work when the teachers were in the breakout rooms. Our webinar facilitators moved in and out of each breakout room to observe and provide assistance, but were only able to address the teachers' questions in one breakout room at a time. Also, the teacher groups worked at different paces - some groups finished a part of the kit quickly and other groups were not able to finish before we needed to move on to the next part.

We used Padlet, an online post-it wall (https://padlet. com), to collect feedback on the webinar. For each part of the kit, the teachers were asked to type into the Padlet online form "Questions I have...", "Likes...", and "Concerns..." The teachers were also asked to provide suggestions for how they might use the kits with their own students. In discussions during the webinar, many of the teachers expressed the need for these types of hands-on activities to keep their students engaged during COVID-19, and the effectiveness of using individual kits for teaching classes in-person (socially distanced) or remotely (online).

\section{DISCUSSION}

Each experience using the kits with the various groups provided new challenges that required adaptation, creativity, and flexibility to overcome. Through innovations in our use of technology, we were able to follow COVID-19-safe guidelines and achieve a high level of engagement. Use of the kits allowed participants to experience hands-on science, regardless of whether the program was remote (online) or in-person (socially distanced). This enabled us to support the educational needs of our community's youth, and to keep them engaged in hands-on, informal science learning during the isolated and uncertain times of the pandemic (Figure 5). We were also able to provide teachers with examples of how to incorporate hands-on learning in their socially distanced classrooms and remote learning environments. The information in Table 1 provides a comparison between traditional (in-person), online, and socially-distanced implementation of the science kits.

It should be noted that we did not collect evaluation data during our use of the kits in the informal science education programs described above, since we were not conducting a research study to compare the effectiveness of using the kits remotely/socially-distanced versus use of the kits in traditional face-to-face instruction (pre-COVID-19). We describe and share our insights from the process of changing delivery mode of the kits to overcome COVID-19-safe challenges leaving open the question of 'do they work' as well or better than they did in pre-COVID-19 modes of instruction. Future research may include collecting data to determine this.

A few of the "lessons learned" from our experiences include:

- For online programs, understand the technological capabilities of the participants. Prepare to support participants in using Zoom. Make sure they can see and hear the program facilitator. Prepare for technology failures such as slow internet connections that prevent participants from using their video camera.

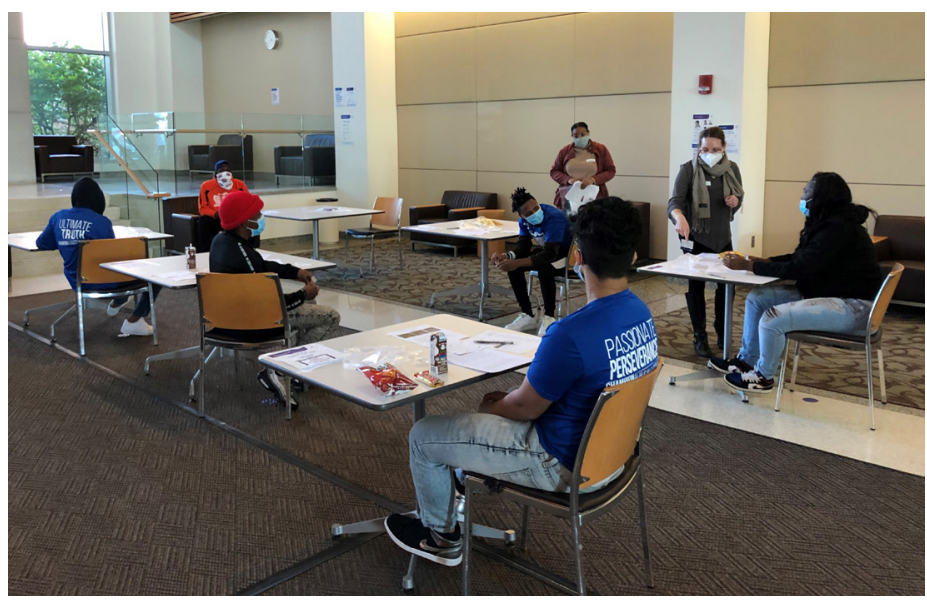

Figure 5. Socially-distanced kit use. 
Table 1. Elements of traditional kit use versus online and socially distanced kit use.

\begin{tabular}{|c|c|c|c|}
\hline & Traditional Kit Use & Online Kit Use & Socially Distanced Kit Use \\
\hline $\begin{array}{l}\text { Location and } \\
\text { Grouping of } \\
\text { Learners }\end{array}$ & $\begin{array}{l}\text { All learners are in the same room/lo- } \\
\text { cation. Learners work together with a } \\
\text { partner or in small groups of } 3-4 \text {. The } \\
\text { facilitator is at the same location as the } \\
\text { learners. }\end{array}$ & $\begin{array}{l}\text { The facilitator and each learner are } \\
\text { at their own location, on their own } \\
\text { device. } \\
\text { - The facilitator is at one location and } \\
\text { the learners are all together at another } \\
\text { location, seated at least } 6 \text { feet apart. }\end{array}$ & $\begin{array}{l}\text { All learners are in the same room/ } \\
\text { location. Learners work individually, } \\
\text { seated at least } 6 \text { feet apart. The facilitator } \\
\text { is at the same location as the learners. }\end{array}$ \\
\hline Sharing of Kits & $\begin{array}{l}\text { One kit is shared with a partner or with } \\
\text { a small group or } 3-4 \text { people. }\end{array}$ & Each learner has their own kit. & Each learner has their own kit. \\
\hline $\begin{array}{l}\text { Distribution of } \\
\text { Kits }\end{array}$ & Facilitator brings the kits to the location. & $\begin{array}{l}\text { - Kits are mailed to each participant. } \\
\text { Kits are mailed to the group leader } \\
\text { who then mails or distributes the kits } \\
\text { to the learners. }\end{array}$ & Facilitator brings the kits to the location. \\
\hline $\begin{array}{l}\text { Facilitator } \\
\text { and Learner } \\
\text { Interaction }\end{array}$ & $\begin{array}{l}\text { Facilitator is in the same room/location } \\
\text { as the learners, to provide face-to-face } \\
\text { support for the activities, answer } \\
\text { individual questions, and engage learn- } \\
\text { ers in individual and group discussions. }\end{array}$ & $\begin{array}{l}\text { Facilitator is online and is able to provide } \\
\text { remote support for the activities, answer } \\
\text { individual questions, and engage learners } \\
\text { in group discussions. Participants can use } \\
\text { "chat" function of Zoom for questions or } \\
\text { comments. }\end{array}$ & $\begin{array}{l}\text { Facilitator is in the same room/location } \\
\text { as the learners, to provide socially } \\
\text { distanced support for the activities, an- } \\
\text { swer individual questions, and engage } \\
\text { learners in individual and group } \\
\text { discussions. }\end{array}$ \\
\hline $\begin{array}{l}\text { Learner-learner } \\
\text { Interaction }\end{array}$ & $\begin{array}{l}\text { Face-to-face, whole group and small } \\
\text { group discussions. }\end{array}$ & $\begin{array}{l}\text { Small group discussions in Zoom } \\
\text { breakout rooms and whole group } \\
\text { discussions. }\end{array}$ & $\begin{array}{l}\text { Face-to-face, whole group and small } \\
\text { group discussions possible - depending } \\
\text { on room set-up. }\end{array}$ \\
\hline
\end{tabular}

- If mailing the kits to the program leader, allow ample time for the leader to distribute the kits to participants. If mailing the kits to individual participants, make sure to have correct mailing addresses and confirm that the kits were received.

- Participants work at different speeds - some work quickly while others lag behind. Prepare some simple activities that participants can do while waiting for others, such as adding their thoughts to a Padlet online post-it wall.

- Providing time for participant discussion is as important as the hands-on component of the kit. Fostering discourse provides participants with a chance to think about the science concepts in the kit, which promotes higher-order learning (Windschitl et. al, 2018).

Other informal (outreach) and formal (classroom) educators can use our creative adaptations within their own educational programs. For example, educators can assemble their own "kits" of materials for hands-on programs. The individual kits can be mailed or distributed to learners for remote or in-person programming.

As COVID-19 pandemic restrictions are lifted, we plan to continue using these kits and other kits for hands-on learning. The kits have allowed us to expand our outreach beyond the Greater Rochester area. We plan to expand our use of the kits nationally through webinars and online programs. For example, we will be exploring collaborations with other science teacher organizations and environmental health organizations to provide hands-on webinars for their members.
Additionally, we are using this online model to create "virtual field trip" programs for middle and high school classes. As COVID-19 restrictions are lifted, many schools will continue to offer remote learning options for their students, therefore continuing to explore best-practices for hands-on learning in this type of environment is important.

\section{AUTHOR INFORMATION Corresponding Author}

Dina G. Markowitz, PhD. University of Rochester, 601 Elmwood Avenue, Box EHSC, Rochester, NY 14642. Dina Markowitz@urmc.rochester.edu

\section{Author Contributions}

The manuscript was written through contributions of all authors. All authors have given approval to the final version of the manuscript.

\section{ACKNOWLEDGMENTS}

The authors would like to thank our partner groups who participated in the programs described in this paper.

\section{FUNDING SOURCES}

The programs and activities described in this article were supported by the following grants from the NIH National Institute of Environmental Health Sciences: R41ES031406, R42ES023706, and P30ES001247. 


\section{ABBREVIATIONS}

CEC: Community Engagement Core; STO: Science TakeOut; GSWNY: Girl Scouts of Western New York; RMSC: Rochester Museum and Science Center; NABT: National Association of Biology Teachers; NGSS: Next Generation Science Standards

\section{REFERENCES}

Kontra, C, Lyons, D, Fischer, S, and Beilock, S. (2015). Physical experience enhances science learning. Psychological Science, 26(6),737-749. http://pss.sagepub.com/content $/ 26 / 6 / 737$

Markowitz, D., and Holt, S. (2011). Simulating science: Manipulative models and small scale simulations that promote learning of complex biological concepts. The Science Teacher, July, 44-48.

NGSS Lead States (2013). Next Generation Science Standards: For States, By States. https://www.nextgenscience.org/ get-to-know.

Windschitl, M., Thompson, J. J., and Braaten, M. L. (2018). Ambitious science teaching. Harvard Education Press.

Young, L.J., and Garcia, X. (2020, October 23). What it's like to be a science teacher In a pandemic. Science Friday. https:// www.sciencefriday.com/articles/stem-remote-learning/

Zacharia, Z.C., and Olympiou, G. (2011). Physical versus virtual manipulative experimentation in physics learning. Learning and Instruction, 21, 317-331. 